\title{
Adventitia as a target for intravascular local drug delivery
}

The adventitia, a relatively neglected layer of the arterial wall, may have a role in the development of restenosis. In addition, adventitial drug delivery, through as yet undefined communication channels, may target events occurring in the intima, media, or adventitia.

\section{Structure of adventitia}

The adventitia is the outer connective tissue layer of arteries, consisting of collagen and elastic fibres with fibroblasts and smooth muscle cells, which are loosely organised to permit vasoconstriction and dilatation. On its inner side, the adventitia is bordered by the external elastic lamina; the outer edge merges into surrounding connective tissue. Although at histological examination the adventitia appears delicate, the inner elastic layer is strong and arterial integrity is maintained when all other layers are removed, for example at endarterectomy. The adventitia contains nerve fibres and lymphatics, as well as a network of small blood vessels, the vasa vasorum. The vasa vasorum consists of arterioles that lead from the adventitia and penetrate the outer media. These vessels provide a blood supply for areas of the vessel too far from the lumen for diffusion of nutrients. Reactions in the adventitia seem to contribute to both intimal thickening and remodelling, the two main pathological processes that, in combination, are thought to determine restenosis.

\section{Adventitia can influence intimal thickening}

Adventitial irritation results in focal intimal thickening and leucocyte infiltration in atherosclerosis, bypass grafts, and restenosis. ${ }^{1-3}$ Markers applied to the adventitia can be visualised in the intima; in addition, deeper injury encroaching on the adventitia from within the lumen produces more extensive intimal thickening. ${ }^{4}$ The mechanism by which changes in the adventitia affect intimal thickening is not known. Part of the response may be through disturbance of the vasa vasorum, because blockage of this network, perhaps through media cell hypoxia, leads to intimal thickening. ${ }^{5}$ Vasa vasorum size, vessel wall proliferation, and atherosclerotic response are correlated ${ }^{6}$ and intimal thickening can be related to adventitial vasa vasorum production in response to an angiogenic factor. ${ }^{7}$ Removal of adventitia initiates intimal thickening, and restoration of an outer arterial layer results in intimal regression. ${ }^{8}$ However, adventitial manipulation also leads to intimal thickening in the absence of vasa vasorum, so the picture is not yet complete. ${ }^{23}$

\section{Adventitia can influence remodelling}

Albeit perhaps in combination with changes in other layers, the adventitia plays a part in mural responses to injury, thereby influencing lumen dimensions in both atherosclerosis and restenosis. Compensatory enlargement with progressive atherosclerosis may prevent obstruction, ${ }^{9}$ but shrinkage of the entire vessel with inflammatory adventitial fibrosis and reduced elasticity ${ }^{10}$ will result in rapid narrowing. Similarly, although intimal hyperplasia occurs after every angioplasty, not all patients get restenosis. Intravascular ultrasound and quantitative angiography confirm that some loss in diameter after angioplasty can be attributed to contraction of the entire artery, paralleling the process of scar formation after wounding. After injury, redistribution of wall stress leads to shrinkage of the area circumscribed by the internal elastic lamina and lumen loss, which can be related to the adventitial reaction. ${ }^{11}{ }^{12}$ Deep injury causes collagen deposition in the adventitia, altering the capacity of the vessel to compensate for intimal thickening; therefore the vessel is more narrowed. An increase in cellularity in association with adventitial inflammation occurs after injury even if this layer is uninjured. ${ }^{13}$ Further work is clearly needed in this area to evaluate the role of the adventitial reaction and other mural influences in remodelling.

\section{Therapeutic targets within intima and media that might respond to adventitial delivery}

Adventitial delivery could be used to deliver any of the previously investigated substances targeted at events in the intima and media. This would include conventional agents that inhibit smooth muscle cell proliferation and matrix formation, and gene therapy.$^{14}$ In normal vessels, the vasa vasorum extends a variable distance into the media only ${ }^{15}$; in association with atherosclerotic plaque, an extensive network of new vessels may reach into the intima. ${ }^{16}$ In a clinical setting potentially therapeutic substances applied to the adventitia will therefore gain access to atherosclerotic and injured intima.

\section{Therapeutic targets within adventitia that might respond to adventitial delivery}

Novel therapeutic strategies directed at events occurring in the adventitia after luminal injury are also possible, although research in this area is sparse. There may be benefits in regulating neovascularisation in ischaemic arteries; new vessel formation could be increased by depositing 
angiogenic factors or the genes for their production into adventitia. Conversely, because new vessel formation into the intima correlates with intimal thickening, perhaps neovascularisation in this direction should be inhibited. Therapy could also be directed at adventitial contraction and remodelling, targeting mediators of adventitial inflammation and contraction. A further approach might be to influence matrix and connective tissue components in the adventitia and prevent scarring. More work is needed to establish the cellular and extracellular changes that occur in this layer after arterial injury, so that other appropriate targets can be selected.

\section{Development of adventitial delivery}

Drug administration into the adventitia may result in high local concentrations for a prolonged period. ${ }^{17}{ }^{18}$ Studies with adventitial deposition on to exposed arteries under direct vision are underway in experimental models. Such surgical approaches are useful for investigating the influence of adventitia on intimal thickening and for testing potential therapeutic agents, but are not practicable for clinical use. Newer developments that mechanically deliver drug through the arterial wall and deposit drug perivascularly are an interesting concept being evaluated in experimental models. The iontophoretic drug delivery catheter propels charged molecules into intima, media, and adventitia. ${ }^{19}$ The needle injection catheter ${ }^{5}$ delivers drug through extensible needles from the lumen, leaving an adventitial depot. ${ }^{20}$ Microparticles delivered with a porous balloon accumulate in the media and adventitia after arterial injury and also act as drug depots. ${ }^{17}$ Further investigations into adventitial delivery systems will lead to additional insights about events occurring in this layer in restenosis. It is clear that novel strategies for treating this important clinical problem in patients may result from such adventitial-targeted approaches.

T Y HUEHNS P GONSCHIOR B HÖFLNG

Medical Department I,

Klinikum Grosshadern Ludwig-Maximilians University D-81377 Munich,

Germany
TYH is supported by the Peel Medical Research Trust, UK.

Booth RFG, Martin JF, Honey AC, Hassall DG, Beesley JE, Moncada S Rapid development of atherosclerotic lesions in the rabbit carotid artery induced by perivascular manipulation. Atherosclerosis 1989; 76:257-68.

2 Prescott MF, McBride KC, Court M. Development of intimal lesions after leukocyte migration into the vascular wall. Am f Pathol 1989;135: 835-46.

3 Kling D, Holzschuh T, Betz E. Temporal sequence of morphological altertions in artery walls during experimental atherogenesis-occurrence of leukocytes. Res Exp Med 1987;187:237-40.

4 Gonschior P, Goetz AE, Huehns TY, Höfling B. A new catheter for prolonged drug application. Coron Art Dis 1995;6:329-34.

5 Nakata Y, Shionoya S. Vascular lesions due to obstruction of the vasa vasorum. Nature 1966;212:1258-9.

6 Heistad DD, Armstrong ML. Blood flow through the vasa vasorum of coronary arteries in atherosclerotic monkeys. Arteriosclerosis 1986;6: 326-31.

7 Edelman ER, Nugent MA, Smith RT, Karnovsky MJ. Basic fibroblast growth factor enhances the coupling of intimal hyperplasia and prolifera-
tion of vasa vasorum in injured rat arteries. 7 Clin Invest 1992;89:465-73.

8 Barker SGE, Tilling LC, Miller GC, Beesley JE, Fleetwood G, Stavri GT, et al. The adventitia and atherogenesis: removal initiates intimal proliferaal. The adventitia and atherogenesis: removal initiates intimal prolifera-
tion in the rabbit which regresses on generation of a "neoadventitia". tion in the rabbit which regress
Atherosclerosis $1994 ; 105: 131-44$.

9 Glagov S, Weisenberg E, Zarins CK, Stankunavicius R, Kolettis GJ Compensatory enlargement of human atherosclerotic coronary arteries. Compensatory enlargement of

10 Pasterkamp G, Wensing PJW, Post MJ, Hillen B, Mali WPTM, Borst C. Paradoxical arterial wall shrinkage may contribute to luminal narrowing of human atherosclerotic femoral arteries. Circulation 1995 91:1444-9.

11 Post MJ, Borst C, Kuntz RE. The relative importance of arterial remodeling compared with intimal hyperplasia in lumen renarrowing after balloon angioplasty. Circulation 1994;89:2816-21.

12 Kakuta T, Currier J, Haudenschild CC, Ryan TJ, Faxon DP. Differences in compensatory vessel enlargement, not intimal formation, account for restenosis after angioplasty in the hypercholesterolemic rabbit model. Circulation 1994;89:2809-15.

13 Gonschior P, Wilensky R, Larisch K, Huehns TY, Goetz AE, Abels C, et al. Healing pattern after arterial stenting. In: Messmer K, Menger M, eds. Applied microcirculation. Berlin: Springer Verlag (in press)

14 Nikol S, Huehns TY, Gonschior P, Höfling B. Myointimal hyperplasia. Crit Ischaem 1995;5:15-27.

15 Wolinsky H, Glagov S. Nature of species differences in the medial distribution of aortic vasa vasorum in mammals. Circ Res 1967;20:409-21.

16 Kumamoto M, Nakasima Y, Sueishi K. Intimal neovascularization in human coronary atherosclerosis: its origin and pathophysiological significance. Hum Pathol 1995;26:450-6.

17 Höfling B, Huehns TY. Intravascular local drug delivery in restenosis. Eur Heart f 1995;16:437-40.

18 Wilensky RL, March KI, Gradus-Pizlo I, Schauwecker D, Michaels M, Robinson J, et al. Regional and arterial localization of radioactive microparticles after local delivery by unsupported or supported porous balloon catheters. Am Heart $\mathcal{Y}$ 1995;129:852-9.

19 Fernandez-Ortiz A, Meyer BJ, Mailhac A, Falk E, Badimon L, Fallon JT, et al. A new approach for local intravascular drug delivery: Iontophoretic balloon. Circulation 1994;89:1518-22.

20 Gonschior P, Pahl C, Huehns TY, Gerhauser F, Erdemci A, Larisch K, et al. Comparison of different local intravascular drug delivery catheter systems. Am Heart f 1995; 130:1174-81. 